\title{
Relationship between Narrow-Band Imaging Magnifying Observation and Pit Pattern Diagnosis in Colorectal Tumors
}

\author{
Nana Hayashi ${ }^{a}$ Shinji Tanaka ${ }^{a}$ Hiroyuki Kanao $^{a}$ Shiro Oka ${ }^{a}$ Shigeto Yoshida ${ }^{a}$ \\ Kazuaki Chayamab \\ Departments of a Endoscopy and ${ }^{b}$ Gastroenterology and Metabolism, Hiroshima University Hospital, \\ Hiroshima, Japan
}

\author{
Key Words \\ Colorectal tumor $\cdot$ Narrow-band imaging $\cdot$ Magnification • \\ Pit pattern
}

\begin{abstract}
Background/Aim: The aim of this study was to examine the relationship between narrow-band imaging (NBI) magnifying observation using the surface pattern as the main evaluation criterion and pit pattern diagnosis on the basis of magnifying observation using a dye in relation to the characteristics of colorectal tumors according to their morphologies. Methods: In this study, NBI observation and pit pattern diagnosis using a dye with magnifying observation were simultaneously performed in our hospital, and the consecutive 786 cases of colorectal lesions (hyperplasia, adenomata and early carcinomas) that had been endoscopically or surgically resected were retrospectively analyzed. NBI magnifying observation was in conformance with the Hiroshima classification and pit pattern diagnosis was in conformance with the Kudo and Tsuruta classification. The relationship between NBI magnifying observation and pit pattern diagnosis and that between NBI magnifying observation and the histological type/invasion depth were examined in relation to colorectal tumor morphology. Results: Type A correspond-
\end{abstract}

ed to the type Il pit pattern, type B corresponded to the type $\mathrm{III}_{S}$, type III and type IV regular pit patterns, type $\mathrm{C} 1$ corresponded to the type $V_{\text {I }}$ slightly irregular pit pattern, type $C 2$ corresponded to the type $V_{1}$ highly irregular pit pattern and type $\mathrm{C} 3$ corresponded to the type $\mathrm{V}_{\mathrm{N}}$ pit pattern. In the protruded type, the irregularity of type $\mathrm{C} 1$ or $\mathrm{C} 2$ lesions agreed with the type $V_{1}$ slightly or highly irregular pit pattern, respectively, in 114 cases (64.0\%). Moreover, the irregularity was higher with NBI magnifying observation than with pit pattern diagnosis in 58 cases (32.6\%). In the superficial type, the irregularity of type $\mathrm{C} 1$ or $\mathrm{C} 2$ lesions agreed with the type $V_{1}$ slightly or highly irregular pit pattern, respectively, in 63 cases (71.6\%). Moreover, the irregularity was higher with NBI magnifying observation than with pit pattern diagnosis in 19 cases (21.6\%). In the case of type $\mathrm{C} 1$ or $\mathrm{C} 2$ lesions, the irregularity tended to be higher with NBI magnifying observation than with pit pattern diagnosis in the protruded type compared to the superficial type $(p=0.087)$. Conclusion: The surface pattern, which was visible in NBI magnifying observation, differed from the pit pattern findings obtained by magnifying endoscopic observation using a dye. Findings were more detailed in pit pattern diagnosis using a dye than in NBI magnifying observation.

Copyright $\odot 2013$ S. Karger AG, Basel

\section{KARGER}

Fax +4161306 1234

E-Mail karger@karger.ch

www.karger.com
(C) 2013 S. Karger AG, Basel

0012-2823/13/0871-0053\$38.00/0

Accessible online at:

www.karger.com/dig
Shinji Tanaka, MD, PhD

Department of Endoscopy, Hiroshima University

1-2-3 Kasumi, Minami-ku

Hiroshima 734-8551 (Japan)

E-Mail colon@ hiroshima-u.ac.jp 


\section{Introduction}

Previously we reported that both surface and vascular pattern are essential for characterization of colorectal tumor using narrow-band imaging (NBI) magnification [1-4]. The surface pattern, which has been termed pit-like structure or white zone, has a crypt opening (CO) and a marginal crypt epithelium (MCE) [5]. Colorectal tumors have a polypoid appearance and the glandular meanders in a complicated manner. It is difficult to adjust the light for NBI observation to perpendicularly illuminate a pit. Therefore, an observation of an actual dark pit is usually difficult. The structure with a CO and MCE appears white and is observed as a pit-like structure in many cases [5]. The microvessels become thicker and their density increases with cancerous cell infiltration and proliferation [6-8]. When CO destruction, inflammatory cell infiltration or stromal reaction occurs, the distribution of microvessels becomes heterogeneous and their shapes become irregular. On the basis of these characteristics, distinctions can be made between tumor/non-tumor and adenoma/carcinoma, and the invasion depth of early carcinoma can be determined [6].

However, the similarity and relationship of the surface pattern visible in NBI magnifying observation to findings obtained in conventional pit pattern diagnosis is so far unknown. In this study, NBI magnifying observation, performed in conformance with the Hiroshima classification with importance given to the surface pattern, was compared with conventional pit pattern diagnosis using a dye, and the characteristics of colorectal tumors were examined in relation to their macroscopic types.

\section{Materials and Methods}

In this study, NBI magnifying observation and pit pattern diagnosis using a dye with magnifying observation were simultaneously performed at the Department of Endoscopy, Hiroshima University Hospital, between March 2005 and August 2011, and the consecutive 786 cases of colorectal lesions, which had been endoscopically or surgically resected, were retrospectively analyzed. Of these, 516 and 270 cases belonged to the protruded and superficial types, respectively, based on macroscopic classification. On the basis of histological characteristics the 786 cases were identified as: hyperplastic polyp (HP)/serrated adenoma (SA; 60 cases: HP 53, SA 7), tubular adenoma/tubulovillous adenoma (TA; 361 cases), mucosal carcinoma (Mca) to submucosal invasive carcinoma less than $1,000 \mu \mathrm{m}$ (SM-s ca; 246 cases) and submucosal invasive carcinoma deeper than 1,000 $\mu \mathrm{m}$ (SM-d ca; 119 cases). In the evaluation of NBI magnifying findings we used the Hiroshima classification (fig. 1) [1-4]. In this classification, type A includes colorectal tumors that are normal or faded in color and whose microvessels are invisible. Type B includes colorectal tumors with a regular surface pattern or a regular meshed capillary network. Type $\mathrm{C}$ includes colorectal tumors with an irregular surface pattern and no particular structure; this type is subclassified into $\mathrm{C} 1-\mathrm{C} 3$. Thus, colorectal tumors are classified on the basis of both their microvascular architecture and surface pattern. In the evaluation of pit pattern findings, we used the Kudo and Tsuruta classification $[8,9]$. The instruments used in this study were a magnifying videoendoscope system (CF-H260AZI; Olympus, Tokyo, Japan). The resected lesions were pathologically diagnosed in accordance with the criteria of the World Health Organization [10]. The macroscopic types were classified as protruded or superficial type [11]. In this study, a carcinoma with SM-s or SM-d ca was defined as having an invasion depth of $1,000 \mu \mathrm{m}$ or more, as described previously [11-14]. The relationship between NBI magnifying observation and pit pattern diagnosis, and that between NBI magnifying observation and the histopathological findings were examined using these cases in relation to the morphologies of the colorectal tumors in these 786 cases. Data were evaluated by the $\chi^{2}$ test, with significance accepted at a $p$ value of $<0.05$.

\section{Results}

Relationship between NBI Magnifying Findings and Pit Pattern Diagnosis in Protruded-Type Lesions

All lesions belonging to type A agreed with those belonging to the type II pit pattern, and $88 \%$ of lesions belonging to type $\mathrm{B}$ agreed with those belonging to the type $\mathrm{III}_{\mathrm{S}}$, type $\mathrm{III}_{\mathrm{L}}$ and type IV pit regular pit patterns. All protruded lesions with both type II pit pattern and type B were SA. The rate of agreement between lesions belonging to type $\mathrm{C} 1$ and those belonging to the type $\mathrm{V}_{\mathrm{I}}$ slightly irregular pit pattern was $66 \%$, that between type $\mathrm{C} 2$ lesions and those with the type $\mathrm{V}_{\mathrm{I}}$ highly irregular pit pattern was 59\%, and that between type C3 lesions and those with the type $\mathrm{V}_{\mathrm{N}}$ pit pattern was $65 \%$. In the case of type $\mathrm{C} 1$ or $\mathrm{C} 2$ lesions, the irregularity was one lank lower in pit pattern diagnosis than in NBI magnifying findings. In other words, $30 \%$ of the lesions belonging to type $\mathrm{C} 1$ agreed with those belonging to the type $\mathrm{III}_{S}$, type $\mathrm{III}_{\mathrm{L}}$ and type IV regular pit patterns, and $41 \%$ of the lesions belonging to type C2 agreed with those belonging to the type $\mathrm{V}_{\mathrm{I}}$ slightly irregular pit pattern (table 1).

\section{Relationship between NBI Magnifying Findings and}

Pit Pattern Diagnosis in Superficial-Type Lesions

All lesions belonging to type A agreed with those belonging to the type II pit pattern, and $81 \%$ of lesions belonging to type $\mathrm{B}$ agreed with those belonging to the type $\mathrm{III}_{S}$, type $\mathrm{III}_{\mathrm{L}}$ and type IV regular pit patterns. The rate of agreement between lesions belonging to type $\mathrm{C} 1$ and 


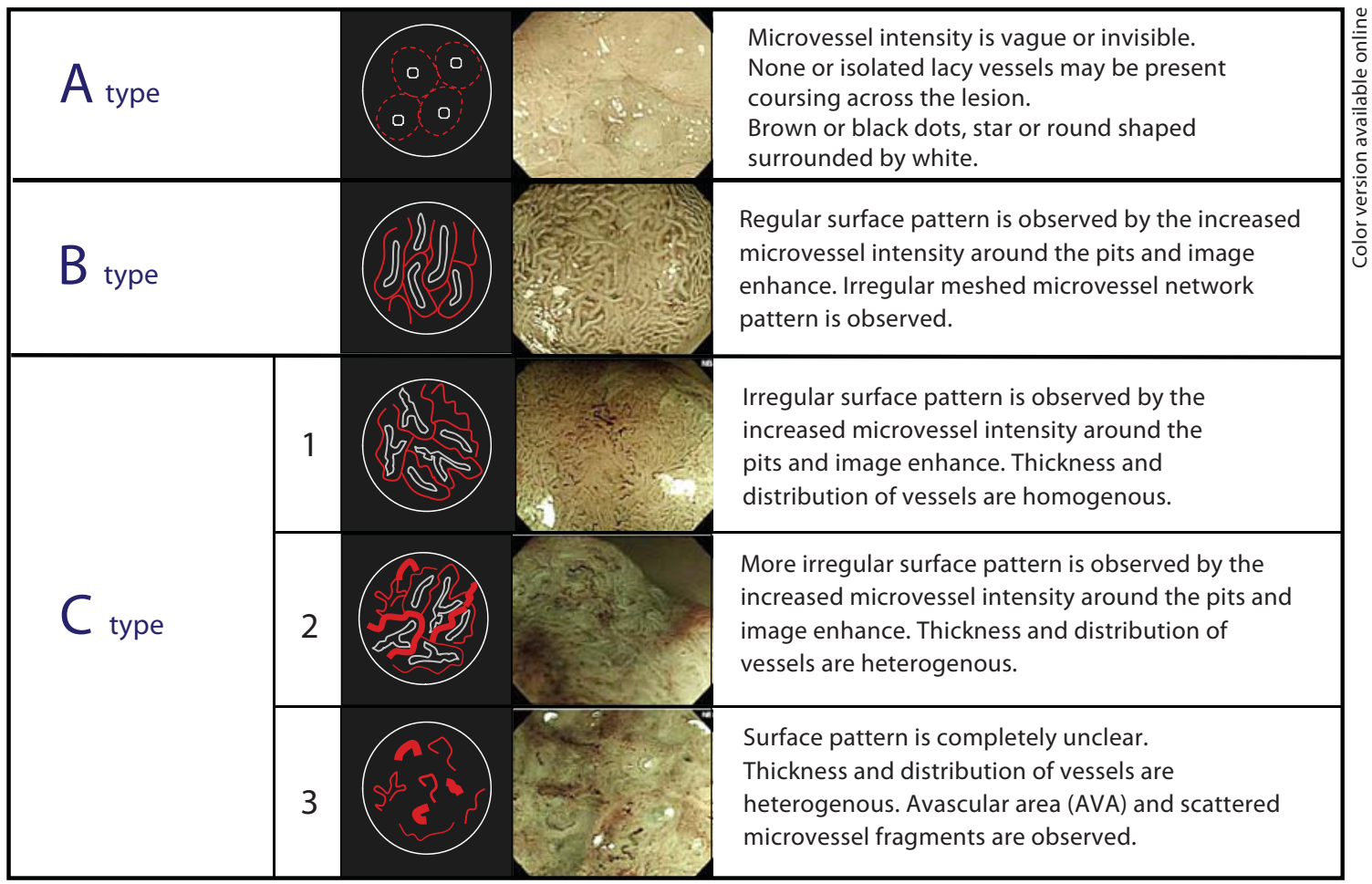

Fig. 1. Hiroshima classification of NBI magnification for colorectal lesions.

Table 1. Relationship between Hiroshima classification of NBI magnification and pit pattern (protruding type)

\begin{tabular}{|c|c|c|c|c|c|c|}
\hline \multirow{2}{*}{$\begin{array}{l}\text { NBI } \\
\text { Hiroshima } \\
\text { classificatior }\end{array}$} & \multirow{2}{*}{$\begin{array}{l}\text { No. of } \\
\text { cases }\end{array}$} & \multicolumn{5}{|c|}{ Pit pattern } \\
\hline & & II & $\mathrm{III}_{\mathrm{S}} / \mathrm{III}_{\mathrm{L}} / \mathrm{IV}$ & $\mathrm{V}_{\mathrm{I}}-\mathrm{L}$ & $\mathrm{V}_{\mathrm{I}^{-}} \mathrm{H}$ & $\mathrm{V}_{\mathrm{N}}$ \\
\hline A & $21(100)$ & \multicolumn{5}{|c|}{$21(100)$} \\
\hline B & $263(100)$ & $5(1)$ & $234(87)$ & $24(12)$ & & \\
\hline $\mathrm{C} 1$ & $137(100)$ & & $41(30)$ & $90(66)$ & $6(4)$ & \\
\hline $\mathrm{C} 2$ & $41(100)$ & & & $17(41)$ & $24(59)$ & \\
\hline $\mathrm{C} 3$ & $54(100)$ & & & & $19(35)$ & $35(65)$ \\
\hline Total & 516 & 26 & 275 & 131 & 49 & 35 \\
\hline
\end{tabular}

Figures in parentheses are percentages.

those belonging to the type $\mathrm{V}_{\mathrm{I}}$ slightly irregular pit pattern was $71 \%$, that between type C2 lesions and those with the type $\mathrm{V}_{\mathrm{I}}$ highly irregular pit pattern was $74 \%$, and that between type $\mathrm{C} 3$ lesions and those with the type $\mathrm{V}_{\mathrm{N}}$ pit pattern was $60 \%$. In the case of type $\mathrm{C} 1$ or $\mathrm{C} 2$ lesions, the irregularity was slightly higher in NBI magnifying findings than in pit pattern diagnosis. In other words, $20 \%$ of the lesions belonging to type $\mathrm{C} 1$ agreed with those
Table 2. Relationship between Hiroshima classification of NBI magnification and pit pattern (superficial type)

\begin{tabular}{|c|c|c|c|c|c|c|}
\hline \multirow{2}{*}{$\begin{array}{l}\text { NBI } \\
\text { Hiroshima } \\
\text { classification }\end{array}$} & \multirow{2}{*}{$\begin{array}{l}\text { No. of } \\
\text { cases } \\
n\end{array}$} & \multicolumn{5}{|c|}{ Pit pattern } \\
\hline & & II & $\mathrm{III}_{S} / \mathrm{III}_{\mathrm{L}} / \mathrm{IV}$ & $\mathrm{V}_{\mathrm{I}}-\mathrm{L}$ & $\mathrm{V}_{\mathrm{I}}-\mathrm{H}$ & $\mathrm{V}_{\mathrm{N}}$ \\
\hline $\mathrm{A}$ & $39(100)$ & $39(100)$ & & & & \\
\hline B & $113(100)$ & & $92(81)$ & 21 (19) & & \\
\hline $\mathrm{C} 1$ & 69 (100) & & $14(20)$ & $49(71)$ & $6(9)$ & \\
\hline $\mathrm{C} 2$ & $19(100)$ & & & $5(26)$ & $14(74)$ & \\
\hline $\mathrm{C} 3$ & $30(100)$ & & & & $12(40)$ & $18(60)$ \\
\hline Total & 270 & 39 & 106 & 75 & 32 & 18 \\
\hline
\end{tabular}

Figures in parentheses are percentages.

belonging to the type $\mathrm{III}_{\mathrm{S}}$, type $\mathrm{III}_{\mathrm{L}}$ and type IV regular pit patterns, and $26 \%$ of the lesions belonging to type $\mathrm{C} 2$ agreed with those belonging to the type $\mathrm{V}_{\mathrm{I}}$ slightly irregular pit pattern. In the case of type $\mathrm{C} 1$ or $\mathrm{C} 2$ lesions, the rate of agreement between NBI magnifying findings and pit pattern diagnosis tended to be higher in the superficial type than in the protruded type $(\mathrm{p}=0.087$; table 2). 

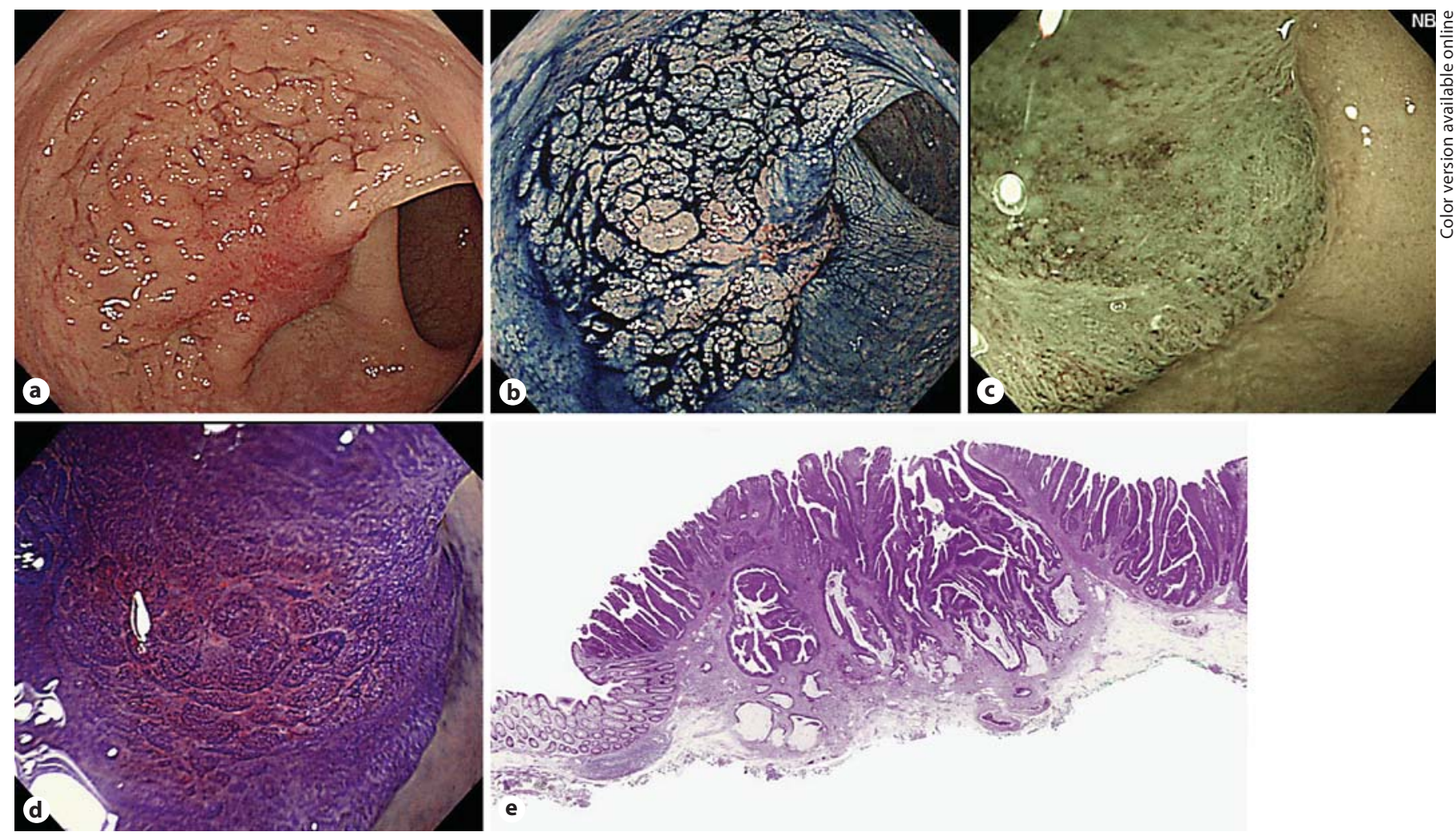

Fig. 2. An LST-G lesion, $50 \mathrm{~mm}$ in diameter. a Standard colonoscopic view. b Standard colonoscopic view with indigo carmine dye spraying. c NBI magnifying colonoscopic view reveals type C3. d Magnifying colonoscopic view with crystal violet staining reveals type $\mathrm{V}_{\mathrm{I}}$ high-grade pit pattern. e Cross section (HE staining). Carcinoma with TA, SM 3,300 $\mu \mathrm{m}$, lyl, v0 tumor margin negative.

Relationship between NBI Magnifying Findings and the Invasion Depth/Histological Type in

Protruded-Type Lesions

All lesions belonging to type A were diagnosed as HP/ SA, $77 \%$ of the lesions belonging to type $B$ were diagnosed as TA, $73 \%$ of the lesions belonging to type $\mathrm{C} 1$ were diagnosed as M-SM-s ca, $54 \%$ of the lesions belonging to C2 were diagnosed as SM-d ca and all lesions belonging to type C3 were diagnosed as SM-d ca (table 3).

\section{Relationship between NBI Magnifying Findings and the Invasion Depth/Histological Type in \\ Superficial-Type Lesions}

All lesions belonging to type A were diagnosed as HP/ SA and $82 \%$ of the lesions belonging to type $\mathrm{B}$ were diagnosed as TA. With regard to type $\mathrm{C} 1,43 \%$ of the lesions were diagnosed as TA and $47 \%$ of the lesions were diagnosed as M-SM-s ca. With regard to type C2, 37\% of the lesions were diagnosed as M-SM-s ca and $63 \%$ of lesions were diagnosed as SM-d ca. All lesions belonging to type $\mathrm{C} 3$ were diagnosed as SM-d ca. In nearly half of the cases that were diagnosed as TA, irregular surface patterns appeared in NBI magnifying findings. In TA the ratio of irregular surface patterns was significantly higher in the superficial type than in the protruded type $(p=0.017$; table 4).

\section{Discussion}

In NBI magnifying findings in conformance with the Hiroshima classification, type A was used as an index for hyperplasia, Type B as an index for intramucosal lesions consisting mainly of adenoma, type $\mathrm{C} 1$ as an index for intramucosal lesions consisting mainly of $\mathrm{M} \mathrm{ca}$ and type $\mathrm{C} 3$ as an index for deep SM-d ca. Although type C2 was used as an index for SM ca, its accuracy was as low as $56.7 \%$. With regard to conventional pit pattern diagnosis 
Table 3. Relationship between Hiroshima classification of NBI magnification and histologic findings (protruding type)

\begin{tabular}{llllrl}
\hline \multirow{2}{*}{$\begin{array}{l}\text { NBI } \\
\text { Hiroshima } \\
\text { classification }\end{array}$} & $\begin{array}{l}\text { No. of } \\
\text { cases }\end{array}$ & \multicolumn{4}{l}{ Histologic findings } \\
\cline { 3 - 6 } & HP/SA & TA & M-SM-s & SM-d \\
\hline A & $21(100)$ & $21(100)$ & & & \\
B & $263(100)$ & $5(1)$ & $199(77)$ & $59(22)$ & \\
C1 & $137(100)$ & & $33(24)$ & $100(73)$ & $4(3)$ \\
C2 & $41(100)$ & & & $19(46)$ & $22(54)$ \\
C3 & $54(100)$ & & & & $54(100)$ \\
\hline Total & 516 & 26 & 232 & 178 & 80 \\
\hline
\end{tabular}

Figures in parentheses are percentages.

in conformance with the Kudo and Tsuruta classification, it was predicted that type A corresponded to the type II pit pattern, type $B$ to the type $\mathrm{III}_{S}$, type $\mathrm{III}_{\mathrm{L}}$ and type IV regular pit patterns, type $\mathrm{C} 1$ to the type $\mathrm{V}_{\mathrm{I}}$ slightly irregular pit pattern, type $\mathrm{C} 2$ to the type $\mathrm{V}_{\mathrm{I}}$ highly irregular pit pattern and type $\mathrm{C} 3$ to the type $\mathrm{V}_{\mathrm{N}}$ pit pattern. Although the rate of agreement between type $\mathrm{A}$ and the type II pit pattern and that between type B and the type $\mathrm{III}_{S}$, type $\mathrm{III}_{\mathrm{L}}$ and type IV regular pit patterns were as high as 100 and $80 \%$, respectively, those between types $\mathrm{C} 1, \mathrm{C} 2$ and $\mathrm{C} 3$ and the corresponding pit patterns were as low as $60-70 \%$.

Regular surface patterns visible in NBI magnifying observation were in almost complete agreement with pit pattern findings, whereas irregular surface patterns visible in NBI magnifying findings did not perfectly agree with pit pattern findings. As mentioned above, the rates of agreement between types C1, C2 and C3 and the corresponding pit patterns were more than $50 \%$. However, the irregularity was one lank lower in pit pattern diagnosis than in NBI magnifying findings. This tendency was observed in both macroscopic types.

As mentioned above, the surface pattern (pit-like structure) visible in NBI magnifying observation differed from an actual pit pattern, and it was obtained by evaluating both the $\mathrm{CO}$ and MCE. Pit pattern diagnosis using magnifying observation with a dye, such as indigo carmine or crystal violet, is the gold standard for fine surface structures of lesions. Therefore, the surface pattern (pitlike structure) visible in NBI magnifying observation was clearly revealed to be inferior to the fine surface structure obtained by pit pattern diagnosis. However, as shown in tables 3 and 4, NBI magnifying observation is also a use-
Table 4. Relationship between Hiroshima classification of NBI magnification and histologic findings (superficial type)

\begin{tabular}{llllll}
\hline $\begin{array}{l}\text { NBI } \\
\text { Hiroshima } \\
\text { classification }\end{array}$ & No. of & \multicolumn{4}{l}{ Histologic findings } \\
\cline { 3 - 6 } cases & HP/SA & TA & M-SM-s SM-d \\
\hline A & $39(100)$ & $39(100)$ & & & \\
B & $113(100)$ & & $93(82)$ & $20(18)$ & \\
C1 & $69(100)$ & & $30(43)$ & $39(57)$ & \\
C2 & $19(100)$ & & & $7(37)$ & $12(63)$ \\
C3 & $30(100)$ & & & & $30(100)$ \\
\hline Total & 270 & 39 & 123 & 66 & 42 \\
\hline
\end{tabular}

Figures in parentheses are percentages.

ful modality for characterizing tumors, similar to pit pattern diagnosis, even though the object to be observed is different. In both protruded and superficial types, the discriminant ability of NBI magnifying observation for adenomata belonging to types B and $\mathrm{C} 1$ differed slightly from that for M-SM-s ca. However, since both adenomata and M-SM-s ca are adaptable to endoscopic therapy, no particular problems are likely to occur when determining therapeutic strategy. Since NBI magnifying observations can be easily performed without any dye, localized colorectal lesions should be first diagnosed qualitatively by using NBI magnifying observation. Conventional pit pattern diagnosis using a dye [15] should be used for lesions belonging to only type $\mathrm{C} 2$ or when the diagnosis is unclear. By this way, colonoscopy can be efficiently performed at low cost.

In lesions possessing regular structures, the fine surface structure centering on the surface pattern (pit-like structure) visible in NBI magnifying observation was in almost perfect agreement with pit pattern findings based on magnifying observation using a dye. However, in lesions possessing irregular structures, irregular findings were more detailed in pit pattern diagnosis based on magnifying observation using a dye than in NBI magnifying observation.

\section{Disclosure Statement}

None of the authors have any disclosures to make. 


\section{References}

1 Oba S, Tanaka S, Matsumoto A, Kanao H, Oka S, Yoshida S, Hiyama T, Ueno Y, Itou K, Kitadai Y, Yoshihara M, Chayama K: Clinical usefulness of NBI (narrow band imaging) magnification for diagnosis of colorectal tumors (in Japanese with English abstract). Stomach Intestine 2010;45:829-840.

-2 Oba S, Tanaka S, Oka S, Toshida S, Shimamoto F, Chayama K: Characterization of colorectal tumors using narrow-band imaging magnification: combined diagnosis with both pit pattern and microvessel features. Scand J Gastroenterol 2010;45:1084-1092.

-3 Kanao H, Tanaka S, Oka S, Hirata M, Yoshida S, Chayama K: Narrow-band imaging magnification predicts the histology and invasion depth of colorectal tumors. Gastrointest Endosc 2009;69:631-636.

4 Tanaka S, Sano Y: Aim to unify the narrow band imaging (NBI) magnifying classification for colorectal tumors: current status in Japan from a summary of the consensus symposium in the 79th annual meeting of the Japan gastroenterological endoscopy society. Dig Endosc 2011;23(suppl 1):131-139.
5 Yao K, Anagnostopoulos GK, Ragunath K: Magnifying endoscopy for diagnosing and delineating early gastric cancer. Endoscopy 2009;41:462-467.

6 Hirata M, Tanaka S, Oka S, Kaneko I, Yoshida S, Yoshihara M, Chayama K: Magnifying endoscopy with narrow band imaging for diagnosis of colorectal tumors. Gastrointest Endosc 2007;65:988-995.

7 Machida H, Sano Y, Hamamoto Y, Muto M, Kozu T, Tajiri H, Yoshida S: Narrow-band imaging in the diagnosis of colorectal mucosal lesions: a pilot study. Endoscopy 2004;36: 1094-1098.

8 Konerding MA, Fait E, Gaumann A: 3D microvascular architecture of pre-cancerous lesions and invasive carcinomas of the colon. Br J Cancer 2001;84:1354-1362.

-9 Kudo S, Hirota S, Nakajima T, Hosobe S, Kusake H, Kobayashi T, Himori M, Yagyuu A: Colorectal tumours and pit pattern. J Clin Pathol 1994;47:880-885.

10 Imai Y, Kudo S, Tsuruta O, Tanaka S, Terai T, Fujii T, Hayashi T: Problems and clinical significance of $\mathrm{V}$ type pit pattern diagnosis: report on round-table consensus meeting (in Japanese). Early Colorectal Cancer 2001;5: 595-613.
11 Hamilton SR, Aaltonen LA (eds): World Health Organization Classification of Tumors: Pathology and Genetics of Tumors of the Digestive System. Lyon, IARC Press, 2000, pp 104-119.

12 Japanese Society for Cancer of the Colon and Rectum: Japanese Classification of Colorectal Carcinoma, English ed 2. Tokyo, Kanehara \& Co. Ltd., 2009.

13 Tanaka S, Haruma K, Oh-E H, Nagata S, Hirota Y, Furudoi A, Amioka T, Kitadai Y, Yoshihara M, Shimamoto F: Conditions of curability after endoscopic resection for colorectal carcinoma with submucosally massive invasion. Oncol Rep 2000;7:783-788.

14 Kitajima K, Fujimori T, Fujii S, Takeda J, Ohkura Y, Kawamata H, Kumamoto T, Ishiguro S, Kato Y, Shimoda T, Iwashita A, Ajioka Y, Watanabe H, Watanabe T, Nagasako K: Correlations between lymph node metasasis and depth of submucosal invasion in submucosal invasive colorectal carcinoma: a Japanese collaborative study. J Gastroenterol 2004;39: 534-543.

15 Tanaka S, Kaltenbach T, Chayama K, Soetikno R: High magnification colonoscopy. Gastrointest Endosc 2006;64:604-613. 